\title{
Article \\ Effect of Vanadium Reinforcement on the Microstructure and Mechanical Properties of Magnesium Matrix Composites
}

\author{
Liqing Sun ${ }^{1}$, Shuai Sun ${ }^{2}$, Haiping Zhou ${ }^{1, *}$, Hongbin Zhang ${ }^{1, *}$, Gang Wang ${ }^{3}$, Chengcai Zhang ${ }^{1}$, Lianfang He ${ }^{2}$ \\ and Xin Wang ${ }^{4}$ \\ 1 College of Mechanical and Electronic Engineering, Shandong University of Science and Technology, \\ Qingdao 266590, China; slqing1123@sdust.edu.cn (L.S.); skd996028@sdust.edu.cn (C.Z.) \\ 2 College of Materials Science and Engineering, Shandong University of Science and Technology, \\ Qingdao 266590, China; 201983050015@sdust.edu.cn (S.S.); skd993978@sdust.edu.cn (L.H.) \\ 3 Shandong Tengda Fasten Tech Co. Ltd., Tengzhou 277599, China; GangWang02@gmail.com \\ 4 School of Materials Science and Engineering, Harbin University of Science and Technology, \\ Harbin 150080, China; frr2834892101@gmail.com \\ * Correspondence: zhouhp@sdust.edu.cn (H.Z.); zhanghb@sdust.edu.cn (H.Z.)
}

\section{check for} updates

Citation: Sun, L.; Sun, S.; Zhou, H.; Zhang, H.; Wang, G.; Zhang, C.; He, L.; Wang, X. Effect of Vanadium Reinforcement on the Microstructure and Mechanical Properties of Magnesium Matrix Composites. Crystals 2021, 11, 806. https:// doi.org/10.3390/cryst11070806

Academic Editors: Hongbin Bei, Raghvendra Singh Yadav and Pavel Lukáč

Received: 20 June 2021

Accepted: 7 July 2021

Published: 10 July 2021

Publisher's Note: MDPI stays neutral with regard to jurisdictional claims in published maps and institutional affiliations.

Copyright: (c) 2021 by the authors. Licensee MDPI, Basel, Switzerland. This article is an open access article distributed under the terms and conditions of the Creative Commons Attribution (CC BY) license (https:// creativecommons.org/licenses/by/ $4.0 /)$.

\begin{abstract}
In this work, vanadium particles $\left(\mathrm{V}_{\mathrm{P}}\right)$ were utilized as a novel reinforcement of AZ31 magnesium $(\mathrm{Mg})$ alloy. The nanocrystalline $(\mathrm{NC}) \mathrm{AZ31}-\mathrm{V}_{\mathrm{P}}$ composites were prepared via mechanical milling (MM) and vacuum hot-press sintering. During the milling process, the presence of $V_{P}$ contributed to the cold welding and fracture mechanism, resulting in the acceleration of the milling process. Additionally, increasing the $\mathrm{V}_{\mathrm{P}}$ content accelerated the grain refinement of the matrix during the milling process. After milling for $90 \mathrm{~h}$, the average grain size of AZ31-X wt \% $V_{p}(X=5,7.5,10)$ was refined to only about $23 \mathrm{~nm}, 19 \mathrm{~nm}$ and $16 \mathrm{~nm}$, respectively. In the meantime, $V_{P}$ was refined to sub-micron scale and distributed uniformly in the matrix, exhibiting excellent interfacial bonding with the matrix. After the sintering process, the average grain size of AZ31- $X$ wt $\% V_{P}(X=5,7.5$, 10) composites still remained at the NC scale, which was mainly caused by the pinning effect of $\mathrm{V}_{\mathrm{P}}$. Besides that, the porosity of the sintered composites was no more than $7.8 \%$, indicating a good densification effect. As a result, there was little difference between the theoretical and real density. Compared to as-cast AZ31 Mg alloy, the microhardness of sintered AZ31-X wt \% $V_{P}(X=5,7.5,10)$ composites increased by $65 \%, 87 \%$ and $96 \%$, respectively, owing to the strengthening mechanisms of grain refinement strengthening, Orowan strengthening and load-bearing effects.
\end{abstract}

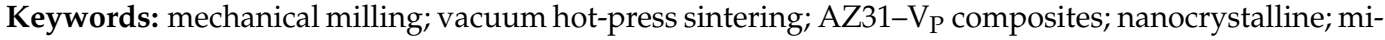
crohardness

\section{Introduction}

The rapid development of high-strength, lightweight alloys is urgently needed for improving energy efficiency in modern industry [1,2]. Magnesium (Mg), as the most promising lightweight metal, has a wide perspective application in aircraft industries, newenergy vehicles, electronic appliances, etc., due to its high specific strength, low density $\left(1.738 \mathrm{~g} / \mathrm{cm}^{3}\right)$ and excellent recyclability [3-5]. However, the low modulus, mechanical strength and poor plasticity of $\mathrm{Mg}$ alloys has seriously limited their large-scale industrial applications [6]. In order to improve their poor mechanical performance, particle-reinforced Mg matrix composites (PRMMCs) have been developed to overcome the disadvantages of $\mathrm{Mg}$ alloys. At present, ceramic particles, such as $\mathrm{SiC}, \mathrm{TiB}_{2}$, and $\mathrm{SiO}_{2}$ [7-9], are the common reinforcements of PRMMCs, which can significantly improve thermal stability, yield strength (YS), modulus, microhardness, fatigue and wear resistance of the $\mathrm{Mg}$ matrix. However, the wettability between ceramic reinforcements and the $\mathrm{Mg}$ matrix is so poor that there is a bottleneck in the further improvement of performance for PRMMCs. Meanwhile, the grain size of many PRMMCs is not fine enough, meaning the advantages of grain 
refinement strengthening cannot be fully exploited for the $\mathrm{Mg}$ matrix. Accordingly, it is important to optimize the reinforcement and matrix of PRMMCs to achieve better mechanical performance.

In recent years, some metal particle reinforcements have been developed to further improve the mechanical performance of PRMMCs, owing to their remarkable strengtheningtoughening effect on Mg alloys. For example, Zhou et al. [10] reported that the AZ31-27 wt \% Ti composites exhibited a high microhardness of $147 \mathrm{HV}$ after cold pressing, which was about three times higher than that of initial AZ31. In addition, pure Mg containing $0.6 \mathrm{vol} \%$ of $\mathrm{Cu}$ nano-powders showed an increase of $40 \%$ in elastic modulus and $51 \%$ in ultimate tensile strength (UTS) [11]. Besides that, the HGM/Mg alloy reinforced with $3 \mathrm{wt}$ $\%$ Ni exhibited high ultimate compressive strengths (UCS) of $403.7 \mathrm{MPa}$ [12]. Similar to the above metal particle reinforcements, the element of vanadium (V) also has characteristics of high hardness, elastic modulus (about three times that of pure Mg) and good ductility [13]. Moreover, $\mathrm{V}$ particles $\left(\mathrm{V}_{\mathrm{P}}\right)$ could be an appropriate dispersion strengthening phase for the $\mathrm{Mg}$ matrix. Besides that, there is no harmful interface reaction between $\mathrm{V}$ and the $\mathrm{Mg}$ matrix to form $\mathrm{Mg}-\mathrm{V}$ intermetallic compounds. Thus, it is worth exploring the feasibility and superiority of $\mathrm{V}$ as a novel particle reinforcement for PRMMCs.

In addition, grain refinement is an effective approach to strengthen PRMMCs. According to the Hall-Petch relationship $\left(\sigma=K_{\gamma} d^{-1 / 2}\right)$ [14], nanocrystalline (NC) and ultra-fine grained (UFG) PRMMCs can exhibit excellent mechanical properties. In particular, due to the high $K_{\gamma}$ values of $\mathrm{Mg}$ alloys [15], the grain refinement strengthening would be very remarkable. Moreover, the ductility of PRMMCs can also be improved via grain refinement, which is caused by the activation of non-basal slip based on the compatibility. For instance, the Mg-2 Gd-0.5 Zr-3 Zn (wt \%) alloy with average grain size of $2.9 \mu \mathrm{m}$ exhibited high YS of $285 \mathrm{MPa}$ and elongation (EL) of 24\% [16]. Yu et al. [17] prepared UFG Ti/AZ31 composites, the YS and EL of which reached $341 \mathrm{MPa}$ and $16 \%$, respectively. On the other hand, the preparation of $\mathrm{Mg}$ alloys can be achieved by various methods, including equal channel angular extrusion pressing (ECAE) [18], high pressure torsion (HPT) [19], friction stir processing (FSP) [20], powder metallurgy (P/M), etc. Among these, the P/M method is an effective and mature technique for preparing PRMMCs, which are fabricated from powders without undergoing a completely melting stage. The advantages of the P/M technique include the homogeneous distribution of particle reinforcements and effective grain refinement [21]. For instance, Ponhan et al. [7] prepared $\mathrm{Mg}-\mathrm{SiC}$ nanocomposites with well-dispersed SiC particles by P/M. Muramatsu et al. [22] fabricated $\mathrm{Mg}_{2} \mathrm{Si} / \mathrm{Mg}$ composites by the $\mathrm{P} / \mathrm{M}$ technique, and significant grain refinement was achieved during the $\mathrm{P} / \mathrm{M}$ process.

In the present work, $\mathrm{V}_{\mathrm{P}}$ was used as a novel reinforcement of $\mathrm{AZ} 31 \mathrm{Mg}$ alloy. The NC AZ31- $V_{P}$ composites with different $V_{P}$ contents were prepared by the $\mathrm{P} / \mathrm{M}$ method, including the processes of mechanical milling and vacuum hot-press sintering. The evolution of powder morphology and $V_{P}$ during the milling process was investigated. Moreover, the effect of $V_{P}$ contents on the microstructure evolution, density and microhardness of AZ31- $V_{P}$ composites was systematically researched. Correspondingly, the microstructure evolution mechanisms and strengthening mechanisms were also analyzed.

\section{Materials and Methods}

The widely used as-cast AZ31 Mg alloy with composition of Mg-3.06 Al-1.01 Zn-0.3 $\mathrm{Mn}-0.028 \mathrm{Si}$ (wt \%) was used as matrix, while the vanadium particle $\left(\mathrm{V}_{\mathrm{P}}\right)$ was used as the reinforcement. The $\mathrm{V}_{\mathrm{P}}$ powders were purchased from Shanghai Naiou Nano technology Co. Ltd., and their average particle size was about $40 \mu \mathrm{m}$. Prior to the milling process, the as-cast AZ31 Mg alloy was cut into chips (0.2 mm in thickness) using a lathe, while the cutting speed and feed rate were chosen as $600 \mathrm{~m} / \mathrm{min}$ and $0.5 \mathrm{~mm} / \mathrm{r}$, respectively. Then, these chips were cleaned by ultrasonic. Figure 1 exhibits the morphology of initial materials. It can be clearly seen that the chips of AZ31 Mg alloy showed laminar morphology, and the $V_{P}$ powders exhibited polygonal shape. 

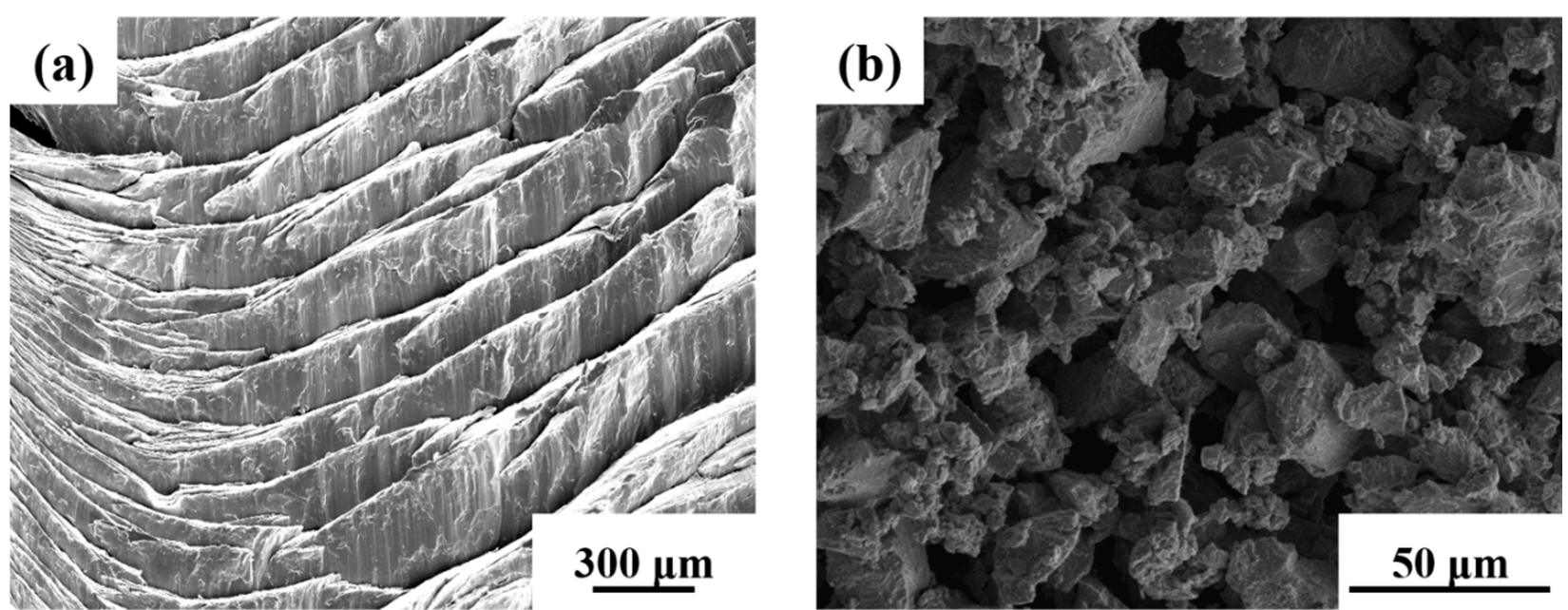

Figure 1. The morphology of initial materials: (a) AZ31 Mg alloy chips and (b) V particles.

The preparation process of $A Z 31-V_{P}$ composites was as follows: Firstly, the AZ31 $\mathrm{Mg}$ alloy chips and $\mathrm{V}_{\mathrm{P}}$ powders were mixed together in a stainless-steel cup filled with argon. In this way, three kinds of mixtures with different $V_{P}$ contents $(5 \mathrm{wt} \%, 7.5 \mathrm{wt} \%$ and $10 \mathrm{wt} \%$ ) were prepared. Then, the mixtures were mechanically milled on a QM-QX4 type ball mill for $90 \mathrm{~h}$. The mill rotation speed was chosen as $200 \mathrm{rpm}$, and the ball ( $\Phi 5 \mathrm{~mm}$, $\Phi 8 \mathrm{~mm}, \Phi 10 \mathrm{~mm}$ ) to powder weight ratio was 60:1. Moreover, in order to avoid oxidation, all the handling steps were performed under argon atmosphere. Finally, the as-milled composite powders (50 g) were put into a graphite mold $(\Phi 35 \mathrm{~mm})$, and consolidated using the vacuum hot-press sintering method. The processing pressure, temperature and holding time were chosen as $300{ }^{\circ} \mathrm{C}, 40 \mathrm{MPa}$ and $1 \mathrm{~h}$, respectively. Figure 2 shows the schematic illustration of vacuum hot-press sintering, and the image of sintered AZ31- $V_{P}$ composites.

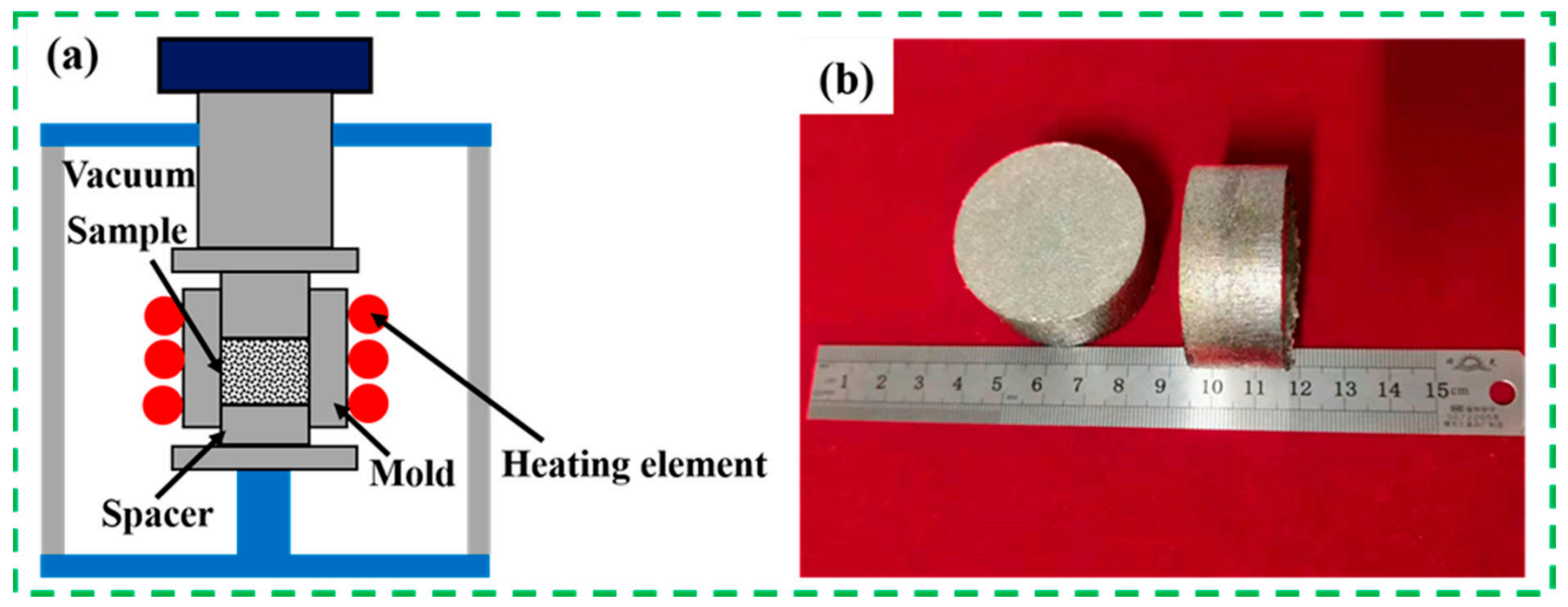

Figure 2. Schematic illustration of vacuum hot-press sintering (a) and image of sintered $A Z 31-V_{P}$ composites (b).

After sintering process, the theoretical density of samples was calculated by using the rule of mixture, which was illustrated in Equation (1) [7]

$$
\rho_{t}=\rho_{m} V_{m}+\rho_{r} V_{r}
$$

where $\rho_{t}$ is the sintered theoretical density. $\rho_{r}$ and $\rho_{m}$ represent the theoretical densities of $\mathrm{V}_{\mathrm{P}}$ and $\mathrm{Mg}$ matrix. $V_{r}$ and $V_{m}$ are the volume fractions of $\mathrm{V}_{\mathrm{P}}$ and $\mathrm{Mg}$ matrix. 
Additionally, the real density of sintered samples was measured by using Archimedes' principle, as expressed in Equation (2) [23]

$$
\rho_{e}=\frac{W_{e}}{\left(W_{e}-W_{w}\right)} \rho_{w}
$$

where $\rho_{e}$ represents the real density of sintered sample, $\rho_{w}$ is the density of distilled water at room temperature, $W_{e}$ and $W_{w}$ are the weight of sample in air and water.

Moreover, the porosity $(P)$ of sintered samples can be calculated via Equation (3) [24]

$$
P(\%)=\left(1-\rho_{e} / \rho_{t}\right) \%
$$

In addition, the powder morphography was analyzed by a FEI APREO scanning electron microscope (SEM) (FEI Company, Hillsboro, OR, USA), and the elemental analysis was conducted by energy dispersive spectrometer (EDS). X-ray diffractometer (XRD) (Rigaku Ultima IV, Rigaku Corporation, Tokyo, Japan) with a Cu- $\mathrm{K} \alpha$ radiation $(40 \mathrm{Kv}$, $40 \mathrm{~mA}$ ) was employed to analyze the phase composition. The scan range and scan speed were chosen as $20-90^{\circ}$ and $4^{\circ} / \mathrm{min}$. Furthermore, transmission electron microscope (TEM) characterization was carried out on a JEM-200 EX TEM (JEOL Ltd., Tokyo, Japan) to further investigate the microstructure of AZ31- $\mathrm{V}_{\mathrm{P}}$ composites. High-resolution TEM (HRTEM) was also utilized to analyze the $\mathrm{Mg} / \mathrm{V}$ interface of the composites.

The microhardness of AZ31- $V_{P}$ composites was examined by using HVS-1000 tester (Shanghai Optical Instrument Factory, Shanghai, China). The load and dwell time were chosen as $200 \mathrm{~g}$ and $15 \mathrm{~s}$, respectively. Meanwhile, at least ten tests for each sample were performed to obtain normalized values.

\section{Results and Discussion}

\subsection{Evolution of Powder Morphology during the Milling Process}

Figure 3 exhibits the evolution of powder morphology for AZ31-5 wt \% $V_{P}$ during the milling process. In the initial stage of milling, many lamellas fractured from the $\mathrm{Mg}$ alloy chips, as shown in Figure 3a,b. Simultaneously, some lamellas piled up together as a result of the cold welding mechanism. In other words, there was a competitive relationship between cold welding and fracture mechanism [25]. With the extension of milling time, the particle size of powders decreased continuously, as shown in Figure 3c-e. This indicated that the fracture mechanism played a predominant role in the evolution of powder morphology. In other words, the particles became hardened and tended to fracture after milling for $50 \mathrm{~h}$, owing to the repeated severe plastic deformation. As a result, the formation of large particles was limited, while the particle size decreased. As the milling time increased to $90 \mathrm{~h}$, it was observed that some equiaxed particles were formed, and the ultimate average particle size was refined to about $635 \mu \mathrm{m}$, as shown in Figure 3e,f. There are two main reasons for the formation of equiaxed particles. Firstly, it is widely proposed that the bigger and harder powder particles were more prone to break, thus inducing the formation of equiaxed particles [26]. Secondly, the occurrence of cold welding could contribute to the formation of equiaxed particles [10]. Similar to the evolution of particle size with the extended milling time, there was also a decreasing trend for the length to width $(\mathrm{L} / \mathrm{W})$ ratio of particles, as indicated in Figure 3a-e. Such phenomenon was mainly attributed to the repeated plastic deformation of powders, which was caused by the high energy impact between the balls and the cup [27]. Through the above discussion, it can be concluded that the finer particle size and the more regular powder shape could be achieved with the increasing milling time. 

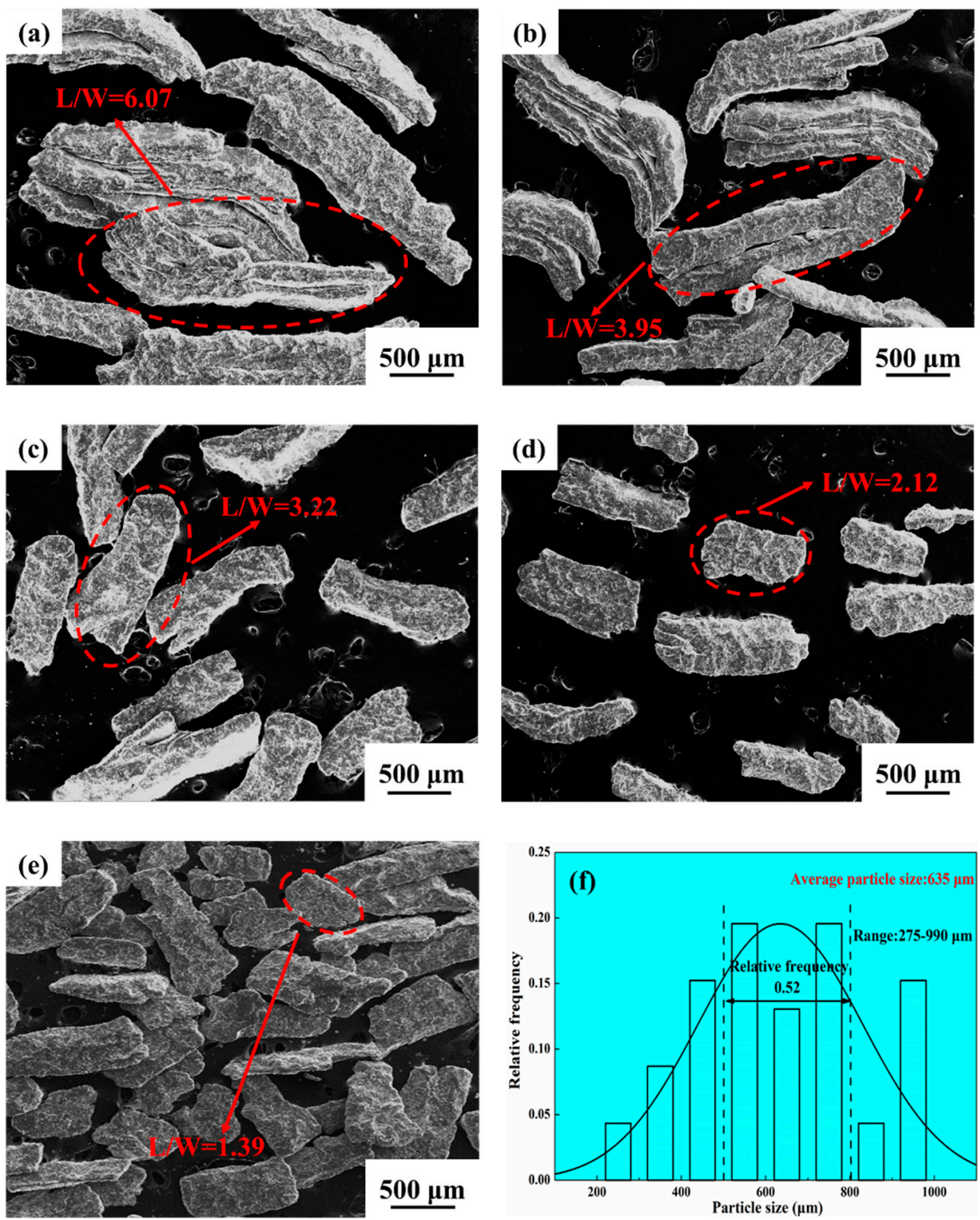

Figure 3. The evolution of powder morphology for AZ31-5 wt \% $V_{P}$ at different milling time: (a) $10 \mathrm{~h}$, (b) $30 \mathrm{~h},(\mathbf{c}) 50 \mathrm{~h},(\mathbf{d}) 70 \mathrm{~h},(\mathbf{e}) 90 \mathrm{~h}$, and the (f) distribution map of particle size for the samples milled for $90 \mathrm{~h}$.

In order to research the influence of $\mathrm{V}_{\mathrm{P}}$ content on the morphology evolution of the composites, the powder morphology of AZ31-X wt \% $V_{P}(X=7.5,10)$ after milling for $50 \mathrm{~h}$ was also analyzed, as shown in Figure 4. By comparison with Figure 3c, it can be observed that the particle size decreased with the increasing content of $V_{P}$, illustrating that the $V_{P}$ accelerated the milling process. Zhou et al. [27] reported a similar phenomenon that the milling process was accelerated by Ti particles. Such phenomenon was mainly attributed to the following reason. The local deformation of the $\mathrm{Mg}$ matrix near the reinforcement particles was enhanced, and the larger local deformation could not only promote the occurrence of cold welding but also induce the fracture [28]. 

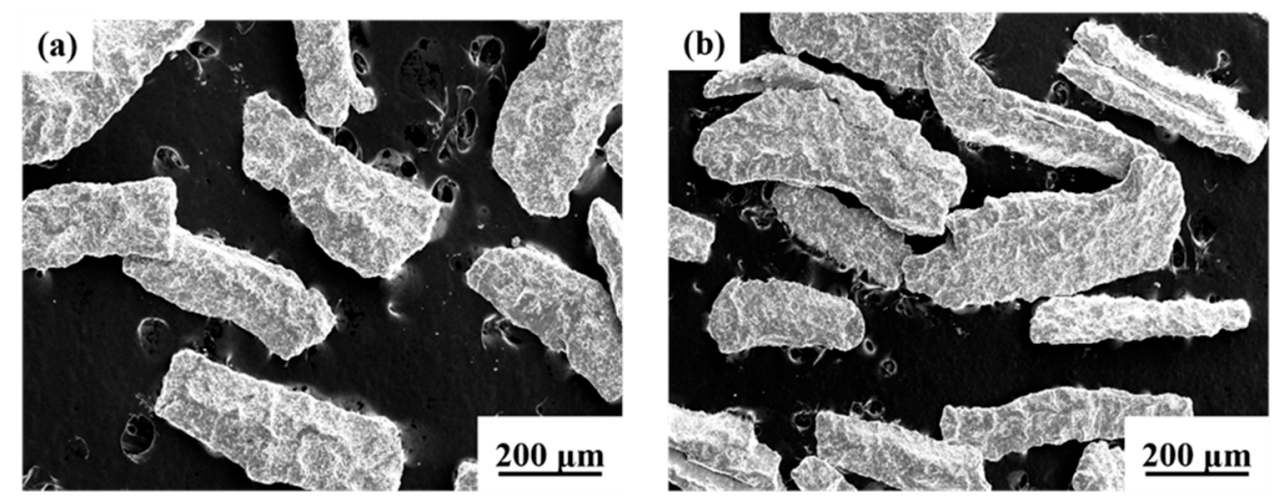

Figure 4. The powder morphology of AZ31 Mg alloy with different $\mathrm{V}_{\mathrm{P}}$ content after milling for $50 \mathrm{~h}$ : (a) $7.5 \mathrm{wt} \%$, (b) $10 \mathrm{wt} \%$.

\subsection{Microstructure of $A Z 31-V_{P}$ Composite Powders \\ 3.2.1. Phase Composition and Matrix Structure}

The XRD patterns of AZ31-X wt $\% V_{P}(X=5,7.5,10)$ powders are illustrated in Figure 5, in which the peaks of the $\mathrm{Mg}$ and $\mathrm{V}$ phases can be observed, and no other phases were detected. Meanwhile, there was no $\mathrm{Mg}_{17} \mathrm{Al}_{12}$ peak in these XRD patterns, which was due to the decomposition of $\mathrm{Mg}_{17} \mathrm{Al}_{12}$ and the dissolving of $\mathrm{Al}$ in the $\mathrm{Mg}$ matrix [29]. Moreover, the peaks of the Mg phase, such as (002) and (101), significantly decreased in diffraction intensity with the increasing milling time. Such phenomenon was mainly caused by the decrease in grain size and accumulation of microstrain. The grain size and microstrain of Mg matrix composites can be calculated via Equations (4) and (5) [30]

$$
\begin{aligned}
& D=\frac{K \lambda}{\beta_{c}^{f} \cos \theta} \\
& e=\frac{1}{4} \beta_{G}^{f} \cot \theta
\end{aligned}
$$

where $D$ is the grain size, $e$ is the microstrain, $K$ is the Scherrer constant, $\lambda$ is the X-ray wavelength, $\theta$ is the Bragg angle. $\beta_{C}^{f}$ and $\beta_{G}^{f}$ can be obtained from the ratio of the Cauchy integral breadth $\left(\beta_{C}^{f} / \beta\right)$ and the Gauss integral breadth $\left(\beta_{G}^{f} / \beta\right)$.

Figure 6 shows the variations in grain size and microstrain of AZ31-X wt $\% V_{P}(X=5$, $7.5,10)$ powders as a function of the milling time. As shown in Figure $6 a$, it can be observed that the grain size of $\mathrm{Mg}$ matrix decreased continuously with the increase of milling time. Meanwhile, the refinement process can be divided into three stages. In the initial stage, the dislocation density gradually increased, due to repeated severe plastic deformation of composite powders. As the increasing dislocation density reached the critical value, the coarse grains split into the sub-grains separated by low angle grain boundaries, resulting in rapid grain refinement [31]. With the formation of many new grain boundaries, the critical value became larger, and thus more energy was required. However, the input mechanical energy was constant during the milling process. As a result, the refinement rate slowed down in the middle stage. As the milling time went over $70 \mathrm{~h}$, there was almost no more refinement for grain size, which reached a relatively stable stage. This was associated with the dynamic balance between grain refinement and grain growth caused by thermal effect [32]. 

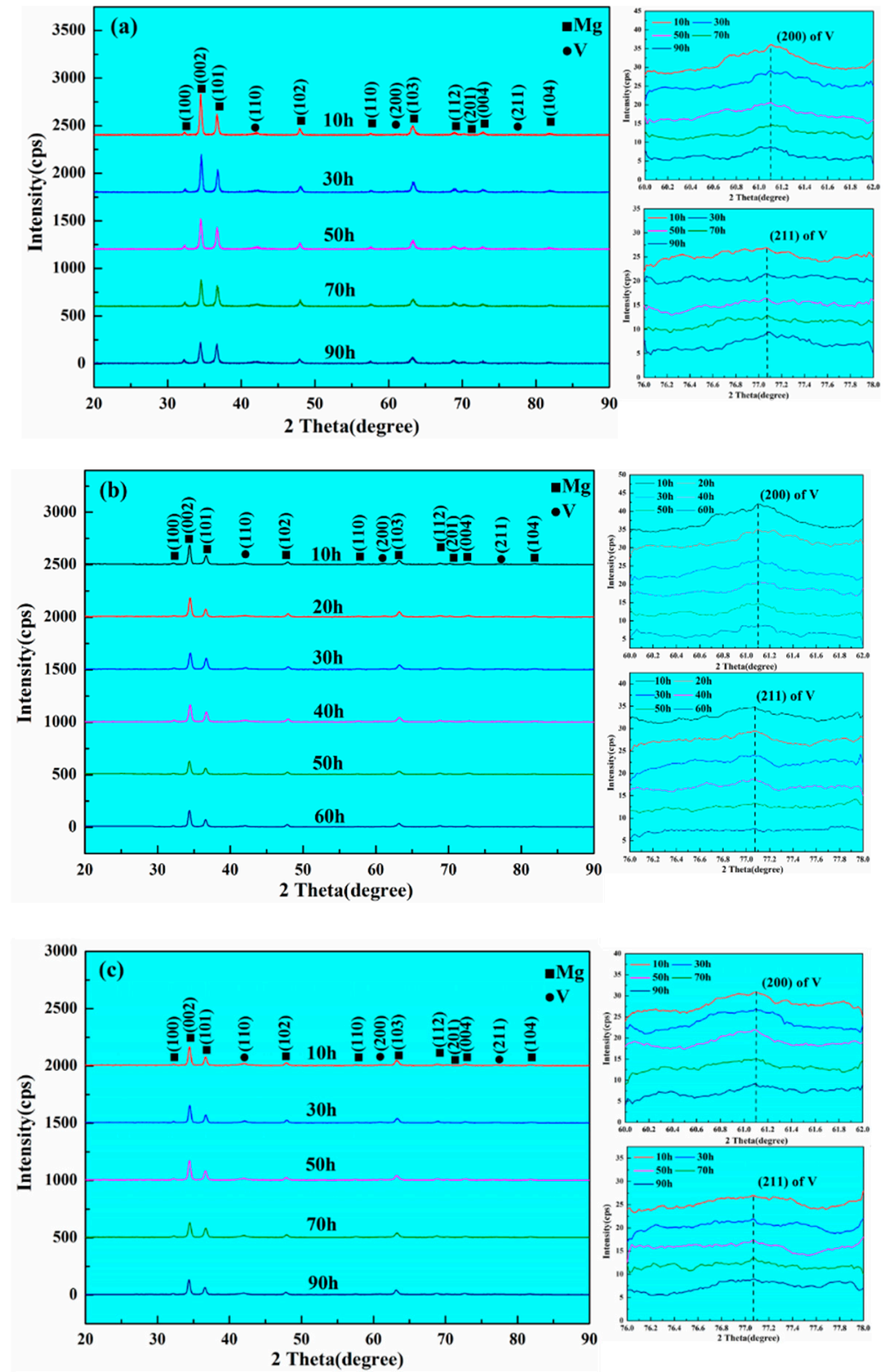

Figure 5. The $X R D$ patterns of $A Z 31-V_{P}$ powders with different $V_{P}$ contents after different milling time: (a) $5 \mathrm{wt} \%$, (b) $7.5 \mathrm{wt} \%$, (c) $10 \mathrm{wt} \%$. The right-sided images are the enlarged XRD patterns of peaks of V (200) and (201), respectively.
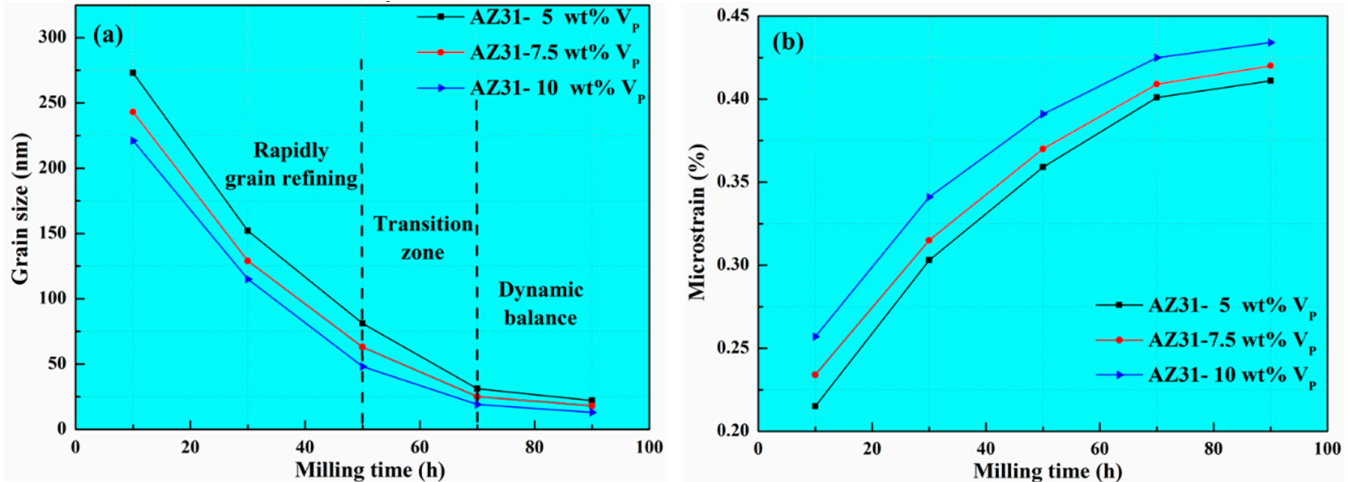

Figure 6. The grain size (a) and microstrain (b) of AZ31- $X$ wt $\% V_{P}(X=5,7.5,10)$ powders after milling for different times. 
Additionally, it should be noticed that the refinement rate increased with the increasing $V_{P}$ content. After milling for $90 \mathrm{~h}$, the average grain size of $A Z 31-X$ wt $\% V_{P}(X=5,7.5,10)$ powders was refined to about $23 \mathrm{~nm}, 19 \mathrm{~nm}$ and $16 \mathrm{~nm}$, respectively, which reached the NC scale. This was partly because of the pinning effect of $\mathrm{V}_{\mathrm{P}}$, which could hinder the migration of grain boundaries and restrain the grain growth. Another primary reason was that the dislocation density would be higher in the composites with the larger $V_{P}$ content, which could lead to the finer grain size. In order to verify the relationship between dislocation density and $V_{P}$ content, the TEM observations of $A Z 31-V_{P}$ powders with different $V_{P}$ contents were carried out, as exhibited in Figure 7. Obviously, the dislocation density increased with the increasing $\mathrm{V}_{\mathrm{P}}$ content under the same milling time. Figure $6 \mathrm{~b}$ exhibits the microstrain of $A Z 31-V_{P}$ powders at different milling times. Contrary to the grain size, the microstrain exhibited an upward trend with the extended milling time, as well as the increasing $\mathrm{V}_{\mathrm{P}}$ content. Such a phenomenon was closely related to the increasing dislocation density, which was caused by the work-hardening and fracture mechanism of powders. It has been reported that the pile up of dislocations could promote the accumulation of microstrain [27].
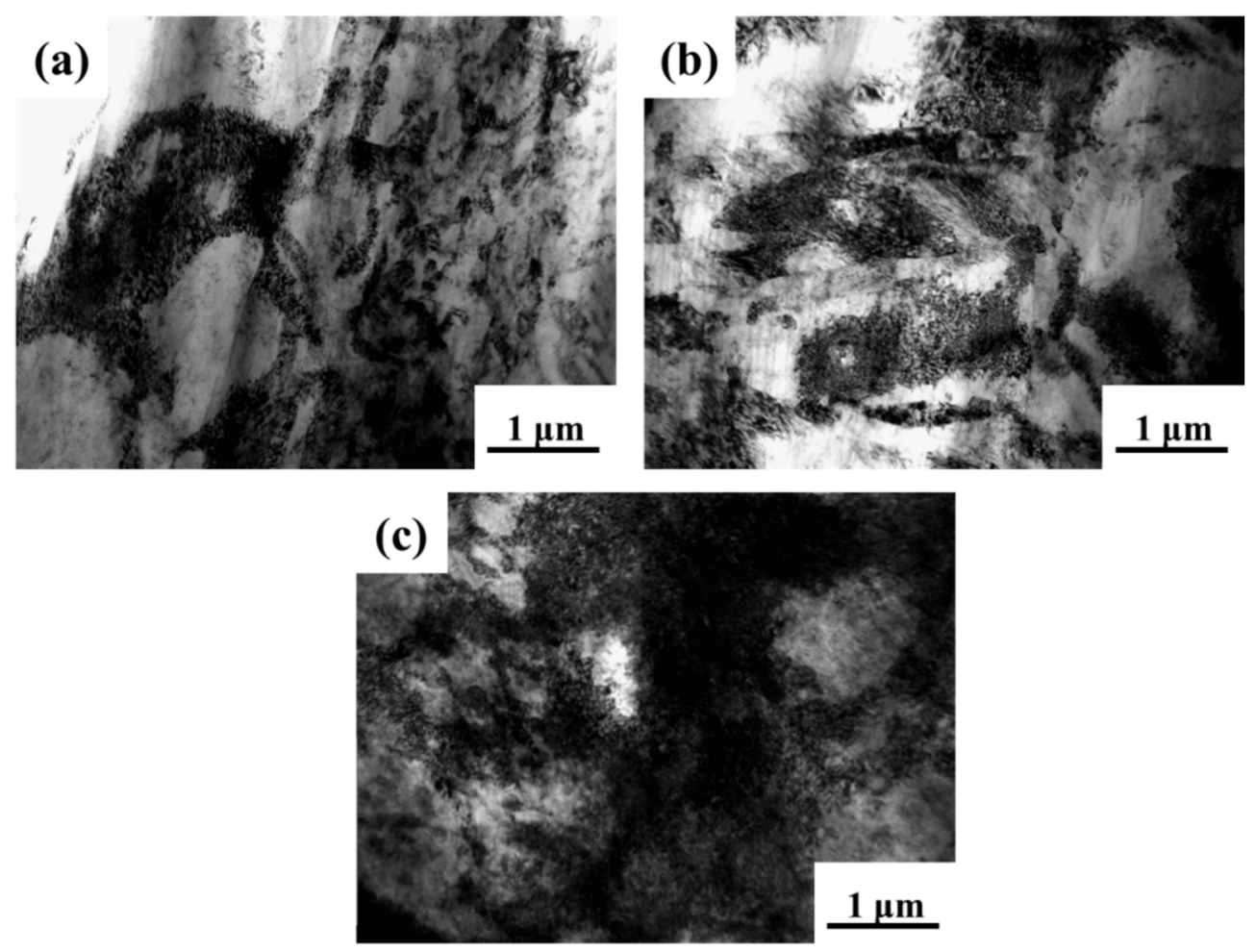

Figure 7. The dislocation density of $A Z 31-V_{P}$ powders with different $V_{P}$ contents after milling for 90 h: (a) $5 \mathrm{wt} \%$, (b) $7.5 \mathrm{wt} \%$, (c) $10 \mathrm{wt} \%$.

Figure 8 displays the TEM images of AZ31-X wt \% $V_{P}(X=5,7.5,10)$ powders after milling for $90 \mathrm{~h}$, as well as the corresponding distribution maps of grain size. According to the selected area diffraction (SAED) pattern in Figure 8a, it can be confirmed that the matrix was Mg. Combined with Figure 8b, it was revealed that the grain size of AZ31-5 wt \% $V_{P}$ powders were mainly distributed between 10 and $30 \mathrm{~nm}$, and the average grain size was approximately $20 \mathrm{~nm}$. As shown in Figure $8 \mathrm{c}-\mathrm{f}$, the average grain size of AZ31-X wt \% $V_{P}$ $(X=7.5,10)$ powders was refined to only about $18 \mathrm{~nm}$ and $14 \mathrm{~nm}$, respectively. By comparison with Figure $6 \mathrm{a}$, it can be indicated that the measured values of grain size were very close to the above calculation results. This verified the accuracy of the calculation results. 

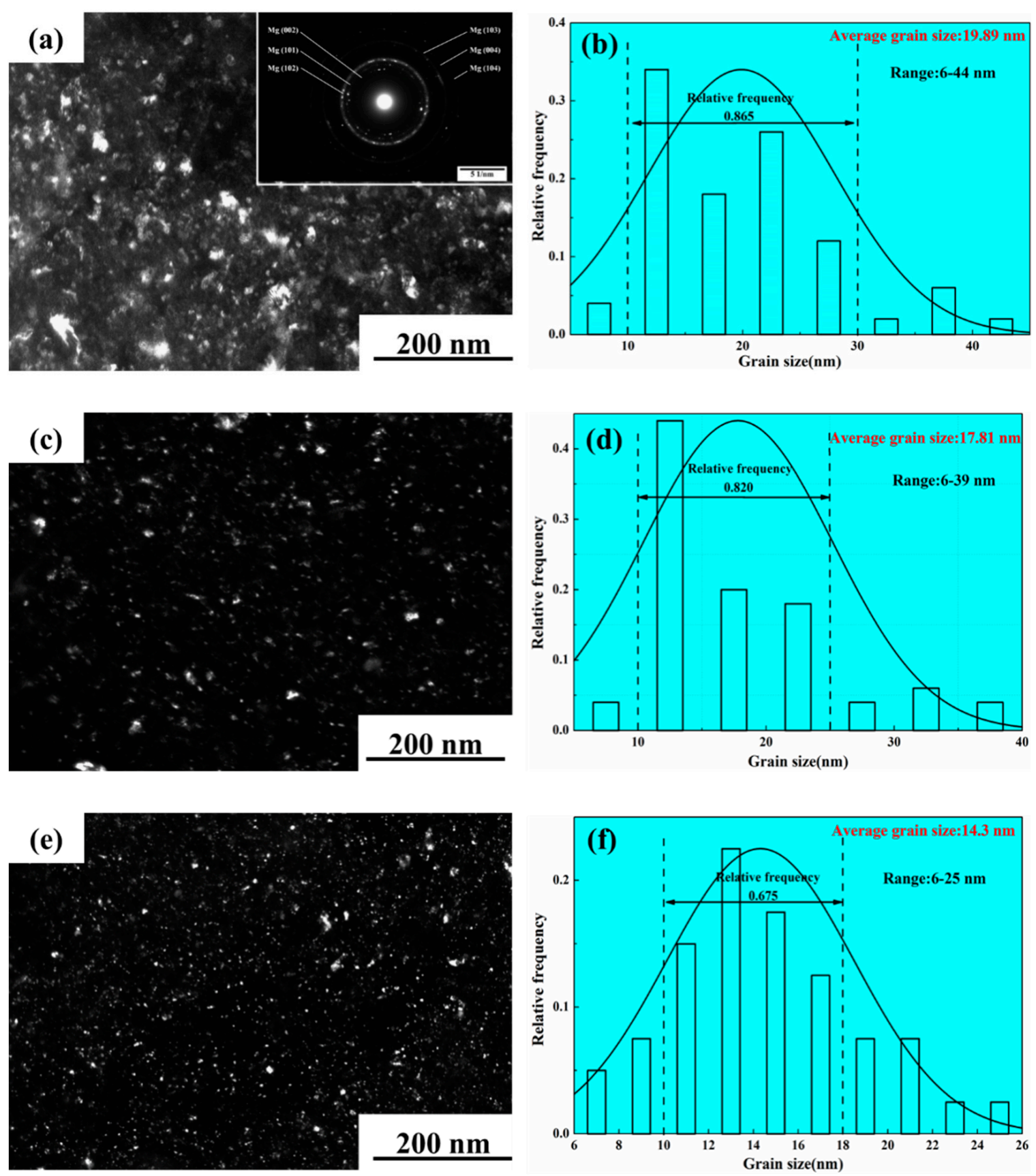

Figure 8. TEM images and corresponding grain size distribution maps of $A Z 31-V_{P}$ powders with different $V_{P}$ contents after milling for $90 \mathrm{~h}$ : (a,b) $5 \mathrm{wt} \%$, (c,d) $7.5 \mathrm{wt} \%$, and (e,f) $10 \mathrm{wt} \%$.

Figure 9 shows the interfacial structure of AZ31-5 wt \% $V_{P}$ powders after milling for $90 \mathrm{~h}$. The $\mathrm{Mg} / \mathrm{V}$ interface can be clearly observed in Figure 9a, which was demonstrated by the SAED patterns and energy dispersive X-ray spectroscopy (EDX) analysis, as given in Figure $9 b, c$. On the basis of the SAED patterns, it can be concluded that the region $A$ was $\mathrm{V}$ and region $\mathrm{B}$ was the $\mathrm{Mg}$ matrix. In addition, the $d$-spacings of regions $\mathrm{C}, \mathrm{D}$ and $\mathrm{E}$ were measured, which were $0.276151,0.259451$ and $0.249874 \mathrm{~nm}$, respectively, as given in Figure $9 \mathrm{~d}-\mathrm{f}$. Combining the XRD data, the corresponding crystal planes were determined to be (100), (002) and (101) of Mg. Through the above analysis, it can be deduced that the $\mathrm{Mg}-\mathrm{V}$ interface formed a close relationship on the above crystal planes. 

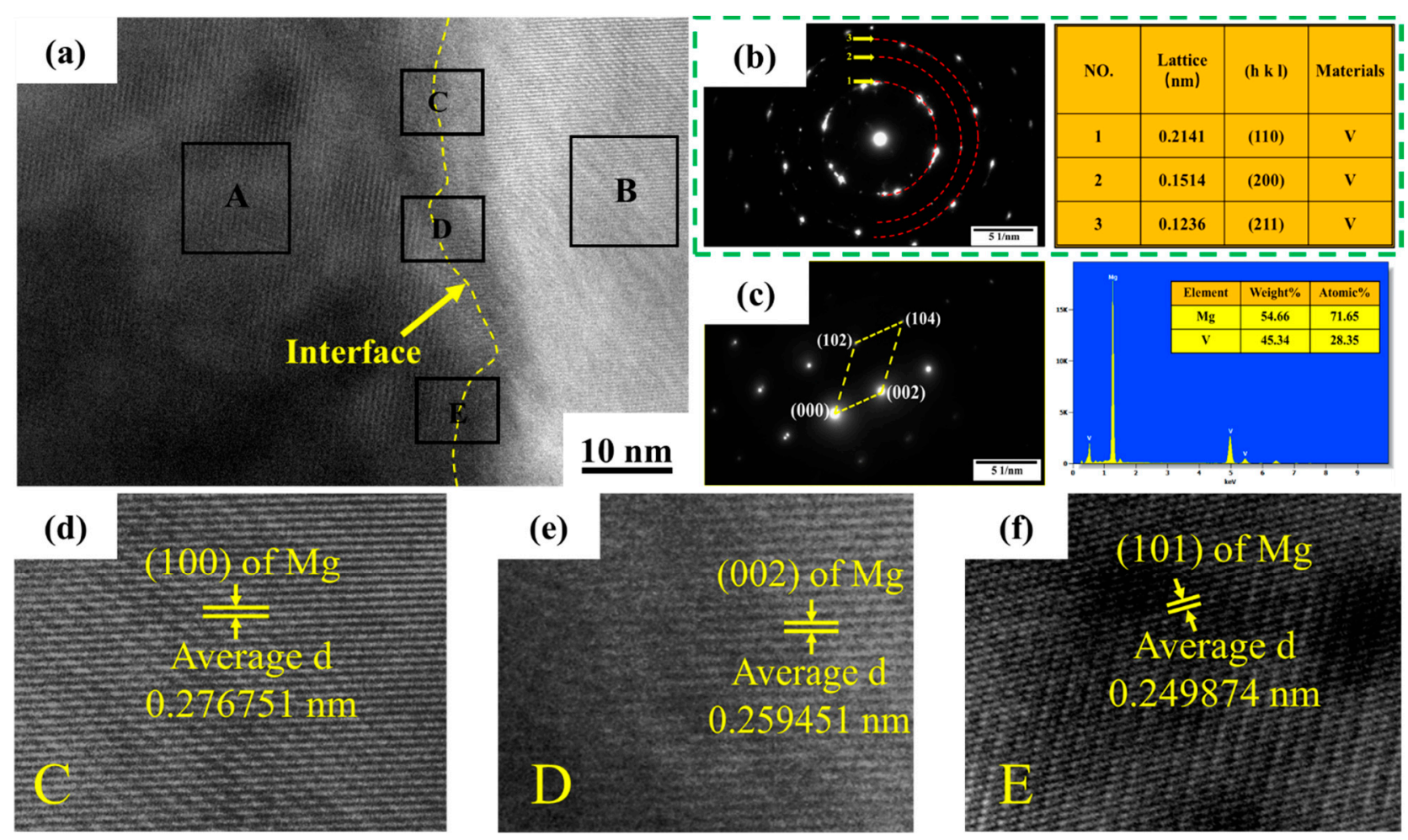

Figure 9. The interfacial structure of AZ31-5 wt \% $V_{P}$ powders after milling for $90 \mathrm{~h}$. (a) HRTEM image, (b) SAED pattern of $\mathrm{V}$ (region A) and its corresponding crystal parameters, (c) SAED pattern of Mg matrix (region B) and EDX result of region $\mathrm{D},(\mathbf{d}-\mathbf{f})$ is the measured $d$-spacing of regions $\mathrm{C}, \mathrm{D}$ and $\mathrm{E}$.

\subsubsection{Evolution of $\mathrm{V}_{\mathrm{P}}$ during the Milling Process}

It is widely recognized that the size and distribution of particle reinforcement was important for improving the mechanical performance of PRMMCs [33,34]. Figure 10a-e exhibits the back scattered electron (BSE) images of AZ31- $5 \mathrm{wt} \% \mathrm{~V}_{\mathrm{P}}$ powders milled for different times. Based on the EDS results of Figure 10g,h, it can be concluded that the gray area of point $\mathrm{A}$ in Figure 10c was the $\mathrm{Mg}$ matrix, while the white particles of point $B$ were $V_{P}$. After milling for $10 \mathrm{~h}$, a large number of $V_{P}$ clusters stuck on the surface of the $\mathrm{Mg}$ matrix, due to the inadequate milling. Meanwhile, some $V_{P}$ existed in the gap between lamellas, as shown in Figure 10a. At $30 \mathrm{~h}$, the quantity and area of $V_{P}$ clusters gradually decreased, but the small $V_{P}$ clusters, marked with the broken circles, still could be observed in the Mg matrix, as shown in Figure 10b. This was caused by the high energy collisions between balls and powders. With the extended milling time, $\mathrm{V}_{\mathrm{P}}$ clusters were continuously disintegrated and more and more $V_{P}$ gradually entered into the matrix, as shown in Figure 10c,d. Similar phenomena were also observed in the other PRMMCs during the milling process $[10,25]$, which was attributed to the cold welding and cracking of particles. With the milling time of $90 \mathrm{~h}, \mathrm{~V}_{\mathrm{P}}$ had distributed uniformly in the matrix, as observed in Figure 10e. Throughout the milling process, the particle size of $V_{P}$ was also gradually refined. The average particle size of $V_{P}$ was only $0.58 \mu \mathrm{m}$ after milling for $90 \mathrm{~h}$, which had reached sub-micron scale, as shown in Figure $10 \mathrm{f}$. 

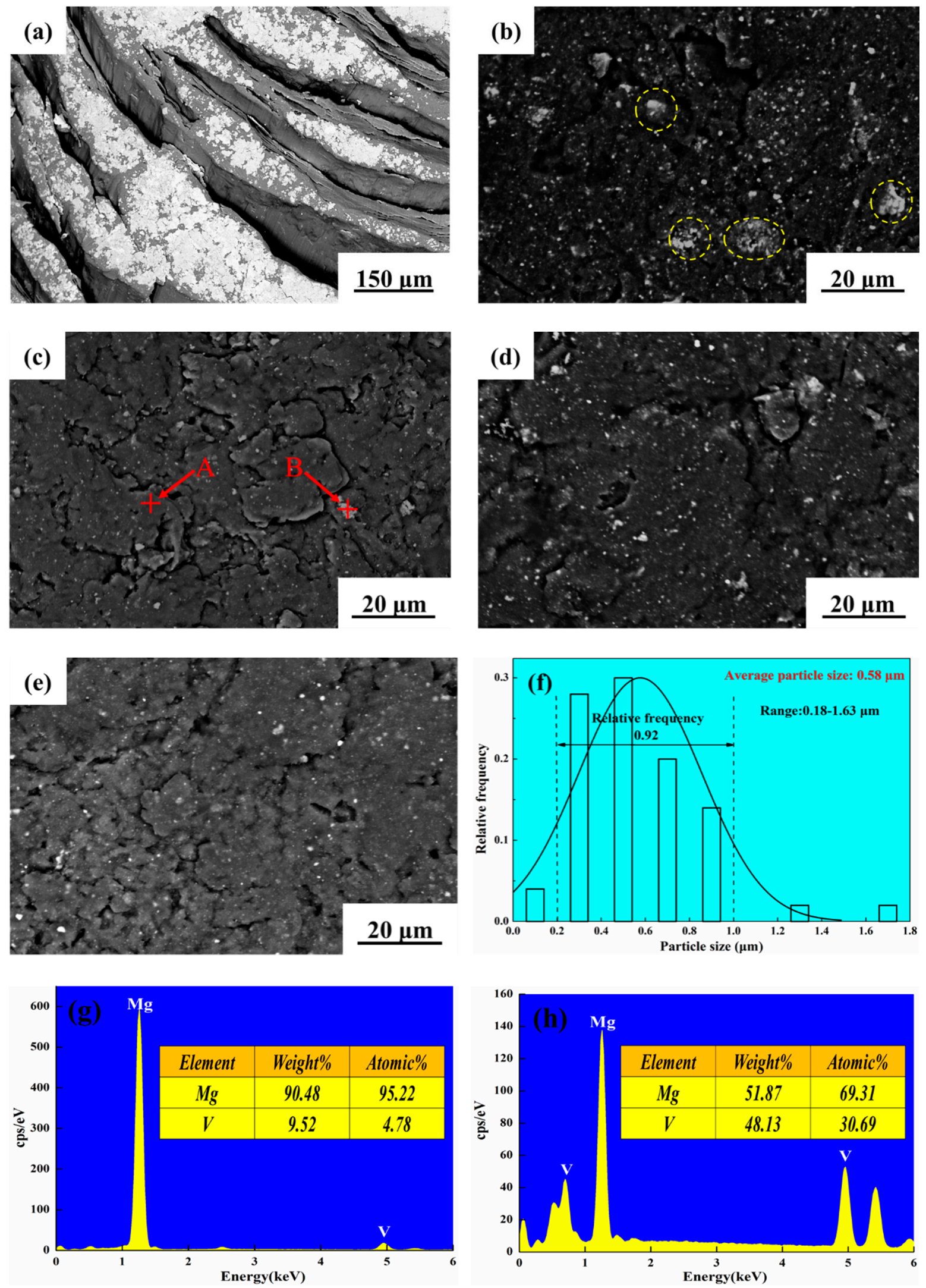

Figure 10. The BSE images of AZ31-5 wt \% V Powders milled for different times: (a) $10 \mathrm{~h},(\mathbf{b}) 30 \mathrm{~h},(\mathbf{c}) 50 \mathrm{~h},(\mathbf{d}) 70 \mathrm{~h}$, (e) $90 \mathrm{~h}$, (f) particle size distribution map of $V_{P}$ after milling for $90 \mathrm{~h},(\mathbf{g}, \mathbf{h})$ EDS results of point $A$ and $\mathrm{B}$. 
In order to further verify the distribution of $\mathrm{V}_{\mathrm{P}}$ in the matrix, the EDS map analysis was carried out, as shown in Figure 11. According to Figure 11b,c, it can be observed that the $\mathrm{V}$ element was uniformly dispersed in the $\mathrm{Mg}$ matrix. From Figure $11 \mathrm{~d}-\mathrm{f}$, it can be observed that most of the $\mathrm{Al}, \mathrm{Mn}$ and $\mathrm{Zn}$ elements were dissolved uniformly in the $\mathrm{Mg}$ matrix. Meanwhile, it should be noticed that the intermetallic compound containing Mn existed in the Mg matrix, which was highlighted by the broken circle in Figure 11e.
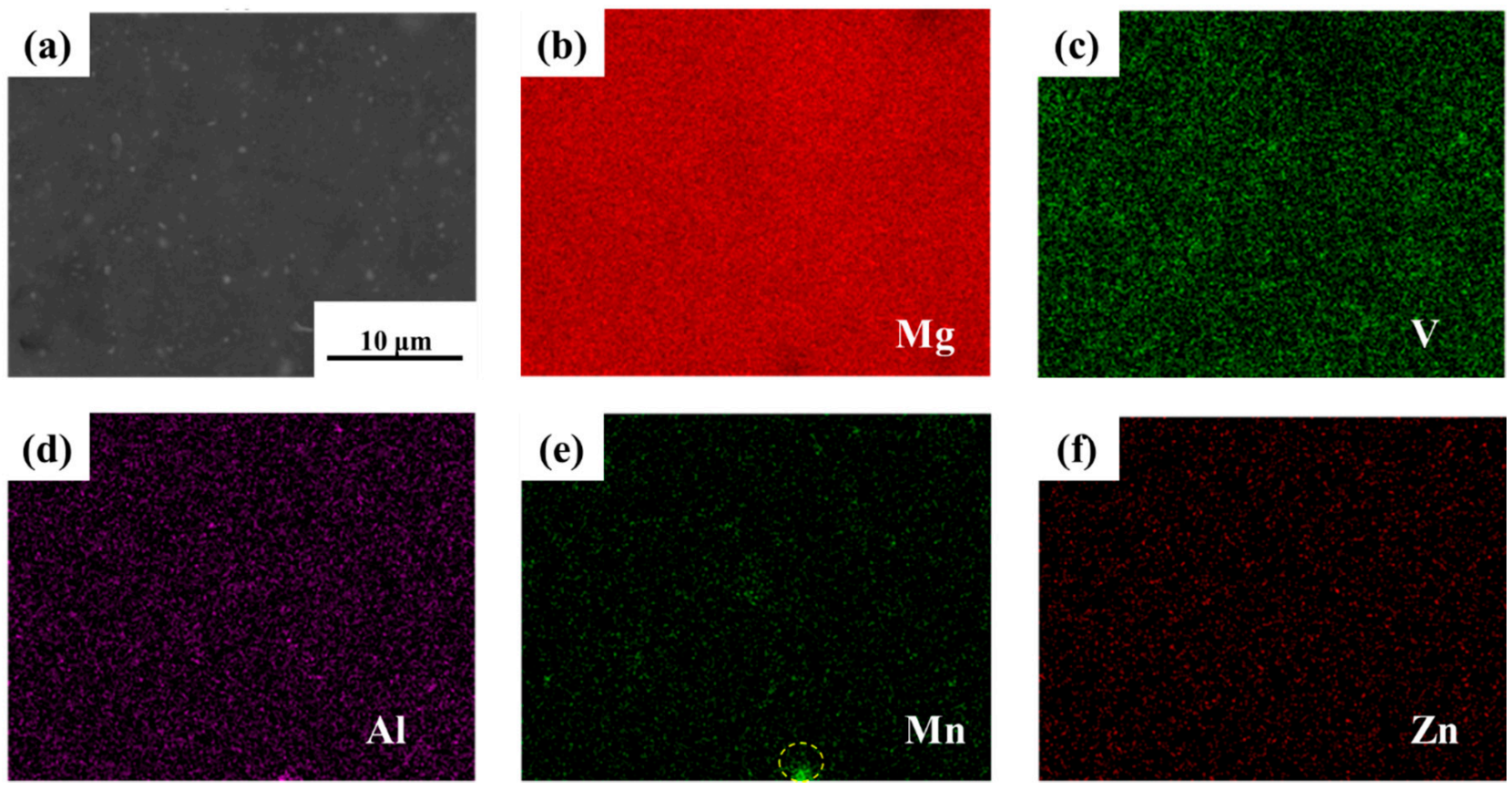

Figure 11. The SEM image (a) and corresponding EDS maps of $\mathrm{Mg}(\mathbf{b}), \mathrm{V}(\mathbf{c}), \mathrm{Al}(\mathbf{d}), \mathrm{Mn}(\mathbf{e})$ and $\mathrm{Zn}(\mathbf{f})$ for the $\mathrm{AZ31}-5 \mathrm{wt} \%$ $\mathrm{V}_{\mathrm{P}}$ powders.

\subsection{Density Evolution and Microstructure of Sintered $A Z 31-V_{P}$ Composites}

After the vacuum hot-press sintering process, the $A Z 31-V_{P}$ composite billets were prepared. According to Equations (1)-(3), the theoretical density, real density and porosity of sintered composites were calculated, as listed in Table 1. Obviously, it can be observed that the porosity of sintered composites increased with the increasing $\mathrm{V}_{\mathrm{P}}$ content. This was because the high content level of $\mathrm{V}_{\mathrm{P}}$ contributed to the increase in porosity, resulting in the occurrence of local cracking [35]. It has been reported [36] that the porosity would significantly influence the quality and the mechanical properties of sintered billets. The high porosity could cause the inhomogeneous distribution of stress across the cross-section, thus reducing the effective load-bearing area [37]. Moreover, both the theoretical density and real density of the sintered composites also increased with the increasing $\mathrm{V}_{\mathrm{P}}$ content, because the density of $\mathrm{V}$ was higher than that of $\mathrm{Mg}$. The similar phenomenon has been reported in the other PRMMCs $[7,17,35]$. Besides that, the maximum theoretical density $\left(1.915 \mathrm{~g} / \mathrm{cm}^{3}\right)$ of sintered composites increased by just $7.6 \%$ compared with the density of the AZ31 Mg alloy, which maintained the advantage of being lightweight.

Table 1. Theoretical, real density and porosity of sintered $A Z 31-V_{P}$ composites.

\begin{tabular}{cccc}
\hline Material & $\begin{array}{c}\text { Theoretical } \\
\text { Density }\left(\mathbf{g} / \mathbf{c m}^{\mathbf{3}}\right)\end{array}$ & $\begin{array}{c}\text { Real } \\
\text { Density }\left(\mathbf{g} / \mathbf{c m}^{\mathbf{3}}\right)\end{array}$ & Porosity (\%) \\
\hline AZ31-5 wt \% $\mathrm{V}_{\mathrm{P}}$ & 1.845 & 1.718 & 6.9 \\
$\mathrm{AZ31-7.5} \mathrm{wt} \mathrm{\%} \mathrm{V}_{\mathrm{P}}$ & 1.879 & 1.741 & 7.3 \\
$\mathrm{AZ31-10}$ wt \% $\mathrm{V}_{\mathrm{P}}$ & 1.915 & 1.766 & 7.8 \\
\hline
\end{tabular}


Figure 12 shows the TEM images of sintered AZ31- $X$ wt $\% V_{P}(X=5,7.5,10)$ composites, and the average grain size of different composites. After the sintering process, the average grain size of AZ31- $X$ wt $\% V_{P}(X=5,7.5,10)$ composites increased to 56,54 and $49 \mathrm{~nm}$, respectively, due to the heat effect. Obviously, the average grain size of sintered AZ31- $\mathrm{V}_{\mathrm{P}}$ composites was below $100 \mathrm{~nm}$, which still remained at the NC scale. The reason for such a phenomenon was the pinning effect of the sub-micron $V_{P}$ during the sintering process [38]. Razavi et al. [39] proposed that the hard reinforcement particles hindered the movement of grain boundaries in the metal matrix during high temperature treatment. Moreover, a high content of reinforcement particles would result in greater inhibition of grain boundary movements and grain growth.
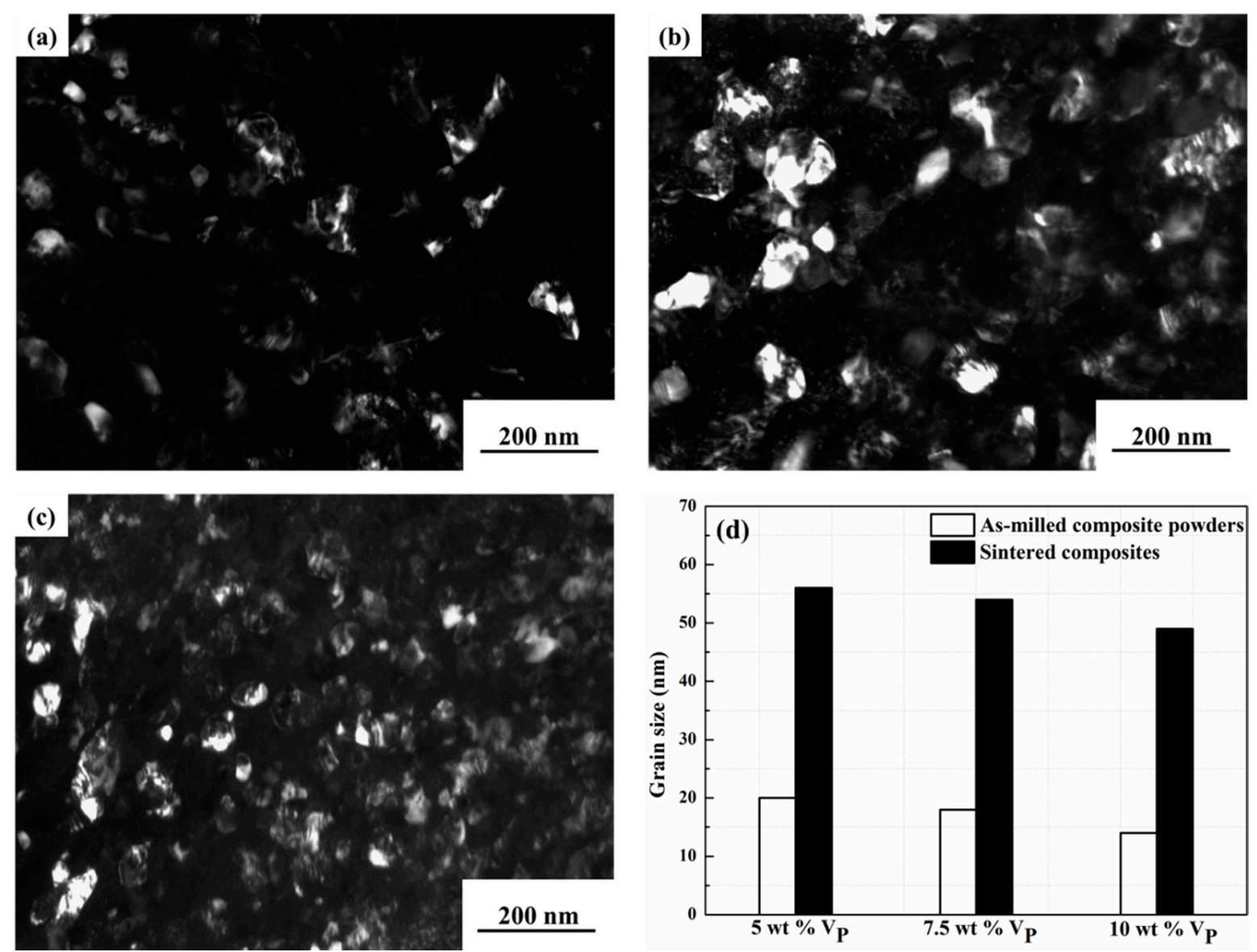

Figure 12. TEM images of sintered $A Z 31-V_{P}$ composites with different $V_{P}$ contents and corresponding grain size: (a) 5 wt $\%$, (b) $7.5 \mathrm{wt} \%$, (c) $10 \mathrm{wt} \%$, (d) average grain size of different composites.

\subsection{Microhardness Analysis}

Figure 13 shows the microhardness of as-cast AZ31 Mg alloy and AZ31- $\mathrm{V}_{\mathrm{P}}$ composites. Compared to as-cast AZ31 Mg alloy, the microhardness of AZ31- $X$ wt $\% V_{P}(X=5,7.5$, 10) composites increased by $65 \%, 87 \%$ and $96 \%$, respectively. Such phenomenon was mainly attributed to the following reasons: Firstly, the average grain size of composites were of NC scale, inducing remarkable grain refinement strengthening. Secondly, Orowan strengthening mechanism was another reason for the increase of microhardness [40]. The well-dispersed sub-micron $V_{P}$ in the matrix obstructed the movement of dislocations, thus causing significant strengthening. Thirdly, good interfacial bonding was formed between the $\mathrm{Mg}$ matrix and $\mathrm{V}_{\mathrm{P}}$, resulting in effective load transfer [41,42]. This strengthening mechanism is generally known as load-bearing effects [43-45]. 


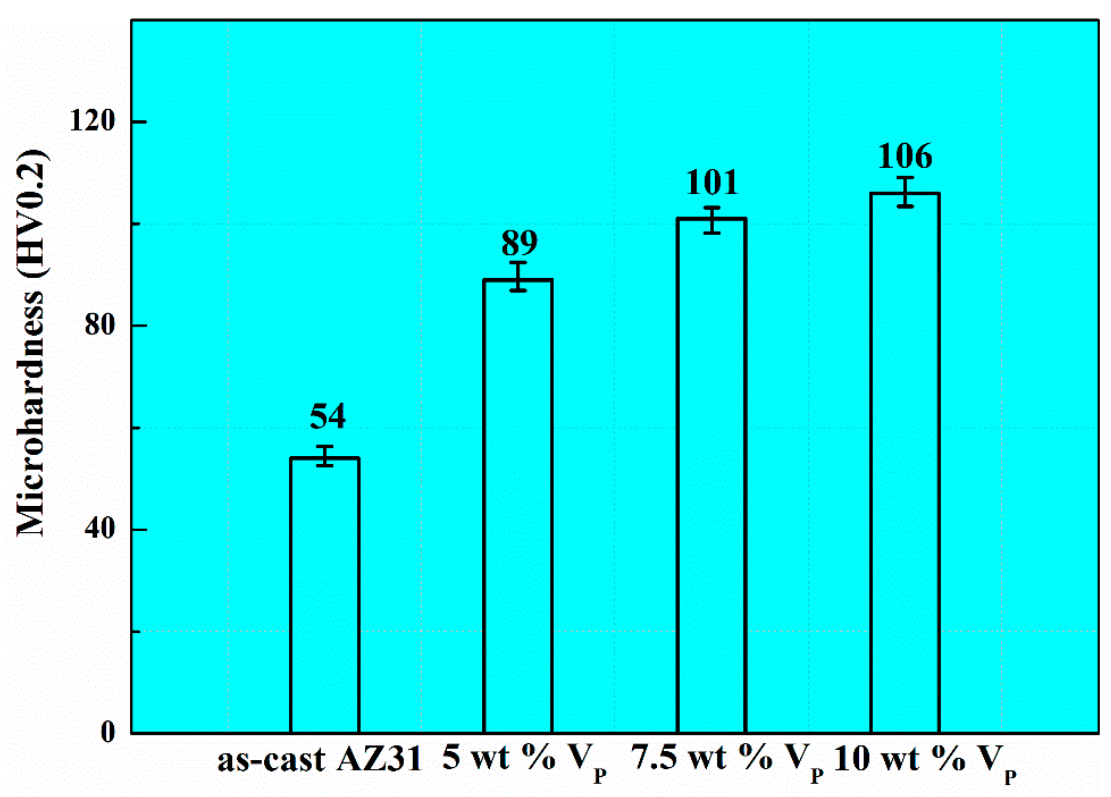

Figure 13. The microhardness of as-cast $A Z 31 \mathrm{Mg}$ alloy and $A Z 31-X$ wt $\% V_{P}(X=5,7.5,10)$ composites.

Besides that, the microhardness of $\mathrm{AZ} 31-\mathrm{V}_{\mathrm{P}}$ composites increased with the increasing weight fraction of $V_{P}$. There were three main reasons for such phenomenon. Firstly, the decrease in grain size enhanced the grain refinement strengthening effect. Secondly, the higher the $V_{P}$ content, the greater the hindrance to dislocation motion. Thirdly, the dislocation density increased with the increasing $V_{P}$ content. In other words, the average distance between dislocations decreased. Therefore, the motion of dislocation was impeded by the other dislocations, thus improving the microhardness [7]. On the other hand, Huang et al. [9] fabricated AZ61 Mg alloy reinforced with $10 \mathrm{Vol} \% \mathrm{SiO}_{2}$, which showed the microhardness of $105 \mathrm{HV}$ and the average grain size of $0.8 \mu \mathrm{m}$. Du et al. [46] prepared the AZ31-0.1 vol \% CNTs composite with the microhardness of $88 \mathrm{HV}$, and the average grain size of $1.5 \mu \mathrm{m}$. By comparison, AZ31-10 wt \% $\mathrm{V}_{\mathrm{P}}$ composite in this work possessed a competitive microhardness of $106 \mathrm{HV}$, and the smallest grain size of $49 \mathrm{~nm}$.

Through the above analysis of microstructure and mechanical property, it can be concluded that $\mathrm{V}_{\mathrm{P}}$ was an excellent novel reinforcement for PRMMCs, while the $\mathrm{P} / \mathrm{M}$ technique was a feasible method for preparing $\mathrm{NC} A Z 31-\mathrm{V}_{\mathrm{P}}$ composites. In future researches, other performance tests of $\mathrm{AZ} 31-\mathrm{V}_{\mathrm{P}}$ composites, including tensile property, compression performance and wear resistance, will be investigated for the large-scale industrial application of $\mathrm{Mg}$ alloys.

\section{Conclusions}

In this work, nanocrystalline (NC) AZ31- $X$ wt $\% V_{P}(X=5,7.5,10)$ composites were successfully prepared via the powder metallurgy method. The powder morphology, microstructure evolution and microhardness of $\mathrm{AZ} 31-\mathrm{V}_{\mathrm{P}}$ composites were also investigated. The main conclusions were drawn as follows:

(1) The presence of $V_{P}$ could contribute to the cold welding and fracture mechanism, resulting in the acceleration of the milling process. Simultaneously, $V_{P}$ was refined to sub-micron scale $(0.58 \mu \mathrm{m})$ and distributed uniformly in the matrix, which also exhibited excellent interfacial bonding with the matrix, after milling for $90 \mathrm{~h}$.

(2) During the milling process, the matrix grain size decreased with the increasing milling time and $V_{P}$ content. After milling for $90 \mathrm{~h}$, the average grain size of AZ31-X wt $\% V_{P}$ $(X=5,7.5,10)$ was refined to only $23 \mathrm{~nm}, 19 \mathrm{~nm}$ and $16 \mathrm{~nm}$, respectively. Besides that, the average grain size of AZ31- $\mathrm{V}_{P}$ composites increased to $56,54,49 \mathrm{~nm}$, respectively, 
after the sintering process, which still remained at NC scale due to the pinning effect of sub-micron $\mathrm{V}_{\mathrm{P}}$.

(3) The porosity of the AZ31- $\mathrm{V}_{\mathrm{P}}$ composites was no more than $7.8 \%$, indicating a good densification effect. Moreover, the effect of small porosity on mechanical properties was little. Compared to as-cast AZ31 Mg alloy, the microhardness of AZ31-X wt \% $\mathrm{V}_{\mathrm{P}}(\mathrm{X}=5,7.5,10)$ composites increased by $65 \%, 87 \%$ and $96 \%$, respectively. The corresponding strengthening mechanisms included grain refinement strengthening, Orowan strengthening and load-bearing effects.

Author Contributions: Conceptualization, L.S. and S.S.; methodology, H.Z. (Hongbin Zhang); validation, H.Z. (Haiping Zhou), C.Z. and G.W.; formal analysis, G.W. and L.H.; investigation, L.S., S.S. and C.Z.; data curation, C.Z. and G.W.; writing-original draft preparation, L.S. and S.S.; writing-review and editing, H.Z. (Haiping Zhou); supervision, H.Z. (Haiping Zhou); project administration, L.H. and X.W.; funding acquisition, H.Z. (Haiping Zhou), H.Z. (Hongbin Zhang) and X.W. All authors have read and agreed to the published version of the manuscript.

Funding: This research was funded by National Natural Science Foundation of China (No. 51904176, 51804187 and 51804091), Project funded by China Postdoctoral Science Foundation (No. 2019M662400 and 2019M662403), Project of Shandong Province Higher Educational Young Innovative Talent Introduction and Cultivation Team [Performance enhancement of deep coal mining equipment.

Data Availability Statement: The data used to support the findings of this study are available from the corresponding author upon request.

Conflicts of Interest: The authors declare no conflict of interest.

\section{References}

1. Suryanarayana, C.; Al-Aqeeli, N. Mechanically alloyed nanocomposites. Prog. Mater. Sci. 2013, 58, 383-502. [CrossRef]

2. Xu, T.; Yang, Y.; Peng, X.; Song, J.; Pan, F. Overview of advancement and development trend on magnesium alloy. J. Magnes. Alloys 2019, 7, 536-544. [CrossRef]

3. Feng, J.; Sun, H.; Li, X.; Zhang, J.; Fang, W.; Fang, W. Microstructures and mechanical properties of the ultrafine-grained Mg-3Al-Zn alloys fabricated by powder metallurgy. Adv. Powder Technol. 2016, 27, 550-556. [CrossRef]

4. Kondo, H.; Hegedus, M. Current trends and challenges in the global aviation industry. Acta Metall. Slovaca 2020, 26, 141-143. [CrossRef]

5. Yeganeh, M.; Mohammadi, N. Superhydrophobic surface of Mg alloys: A review. J. Magnes. Alloys 2018, 6, 59-70. [CrossRef]

6. Asgharzadeh, H.; Yoon, E.Y.; Chae, H.J.; Kim, T.S.; Lee, J.W.; Kim, H.S. Microstructure and mechanical properties of a Mg-Zn-Y alloy produced by a powder metallurgy route. J. Alloys Compd. 2014, 586, 95-100. [CrossRef]

7. Ponhan, K.; Tassenberg, K.; Weston, D.; Nicholls, K.G.M.; Thornton, R. Effect of SiC nanoparticle content and milling time on the microstructural characteristics and properties of $\mathrm{Mg}-\mathrm{SiC}$ nanocomposites synthesized with powder metallurgy incorporating high-energy ball milling. Ceram. Int. 2020, 46, 26956-26969. [CrossRef]

8. Wang, H.Y.; Jiang, Q.C.; Wang, Y. Fabrication of $\mathrm{TiB}_{2}$ participate reinforced magnesium matrix composites by powder metallurgy. Mater. Lett. 2004, 58, 3509-3513. [CrossRef]

9. Lee, C.J.; Huang, J.C.; Hsieh, P.J. Mg based nano-composites fabricated by friction stir processing. Scr. Mater. 2006, 54, 1415-1420. [CrossRef]

10. Zhou, H.; Hu, L.; Sun, Y.; Zhang, H.; Duan, C.; Yu, H. Synthesis of nanocrystalline AZ31 magnesium alloy with titanium addition by mechanical milling. Mater. Charact. 2016, 113, 108-116. [CrossRef]

11. Wong, W.L.E.; Gupta, M. Development of $\mathrm{Mg} / \mathrm{Cu}$ nanocomposites using microwave assisted rapid sintering. Compos. Sci. Technol. 2007, 67, 1541-1552. [CrossRef]

12. Liu, L.; Yu, S.; Liu, E.; Zhao, Y.; Wang, B.; Niu, Y. Effect of Ni addition on the mechanical and degradation properties of hollow glass microsphere/Mg alloy composites. J. Alloys Compd. 2021, 853. [CrossRef]

13. Li, X.; Zhang, H.; Lu, S.; Li, W.; Zhao, J.; Johansson, B.R.; Vitos, L. Elastic properties of vanadium-based alloys from first-principles theory. Phys. Rev. B 2012, 86, 2867-2875. [CrossRef]

14. Meyers, M.A.; Mishra, A.; Benson, D.J. Mechanical properties of nanocrystalline materials. Prog. Mater. Sci. 2006, 51, 427-556. [CrossRef]

15. Yuan, W.; Panigrahi, S.K.; Su, J.Q.; Mishra, R.S. Influence of grain size and texture on Hall-Petch relationship for a magnesium alloy. Scr. Mater. 2011, 65, 994-997. [CrossRef]

16. Hu, Y.; Zhang, C.; Zheng, T.; Pan, F.; Tang, A. Strengthening Effects of Zn Addition on an Ultrahigh Ductility Mg-Gd-Zr Magnesium Alloy. Materials 2018, 11, 1942. [CrossRef] 
17. Yu, H.; Zhou, H.; Sun, Y.; Ren, L.; Hu, L. Microstructures and mechanical properties of ultrafine-grained Ti/AZ31 magnesium matrix composite prepared by powder metallurgy. Adv. Powder Technol. 2018, 29, 3241-3249. [CrossRef]

18. Gzyl, M.; Rosochowski, A.; Boczkal, S.; Olejnik, L. The role of microstructure and texture in controlling mechanical properties of AZ31B magnesium alloy processed by I-ECAP. Mater. Sci. Eng. A 2015, 638, 20-29. [CrossRef]

19. Stráská, J.; Janeček, M.; Gubicza, J.; Krajňák, T.; Yoon, E.Y.; Kim, H.S. Evolution of microstructure and hardness in AZ31 alloy processed by high pressure torsion. Mater. Sci. Eng. A 2015, 625, 98-106. [CrossRef]

20. Del Valle, J.A.; Rey, P.; Gesto, D.; Verdera, D.; Jiménez, J.A.; Ruano, O.A. Mechanical properties of ultra-fine grained AZ91 magnesium alloy processed by friction stir processing. Mater. Sci. Eng. A 2015, 628, 198-206. [CrossRef]

21. Veronesi, P.; Colombini, E.; Rosa, R.; Leonelli, C.; Garuti, M. Microwave processing of high entropy alloys: A powder metallurgy approach. Chem. Eng. Process. 2017, 122, 397-403. [CrossRef]

22. Muramatsu, H.; Kondoh, K.; Yuasa, E.; Aizawa, T. Mechanical Properties of $\mathrm{Mg}_{2} \mathrm{Si} / \mathrm{Mg}$ Composites via Powder Metallurgy Process. JSME Int. J. 2015, 46, 247-250. [CrossRef]

23. Dlapka, M.; Danninger, H.; Gierl, C.; Lindqvist, B. Defining the pores in PM components. Met. Powder Rep. 2010, 65, 30-33. [CrossRef]

24. Zaludin, M.; Jamaludin, S.B.; Idris, M.S.; Llah, N.A. Effect of $45 S 5$ Bio-Glass Particles on Physical Properties and Corrosion Resistance of the Mg-5Zn Matrix Composite. Open J. Met. 2014, 4, 1-8. [CrossRef]

25. Zhou, H.; Zhang, C.; Han, B.; Qiu, J.; Zhang, H. Microstructures and Mechanical Properties of Nanocrystalline AZ31 Magnesium Alloy Powders with Submicron $\mathrm{TiB}_{2}$ Additions Prepared by Mechanical Milling. Crystals 2020, 10, 550. [CrossRef]

26. Fogagnolo, J.B.; Velasco, F.; Robert, M.H.; Torralba, J.M. Effect of mechanical alloying on the morphology, microstructure and properties of aluminium matrix composite powders. Mater. Sci. Eng. A 2003, 342, 131-143. [CrossRef]

27. Zhou, H.; Hu, L.; Sun, H.; Chen, X. Synthesis of nanocrystalline Mg-based Mg-Ti composite powders by mechanical milling. Mater. Charact. 2015, 106, 44-51. [CrossRef]

28. Hesabi, Z.R.; Simchi, A.; Reihani, S.M.S. Structural evolution during mechanical milling of nanometric and micrometric $\mathrm{Al}_{2} \mathrm{O}_{3}$ reinforced Al matrix composites. Mater. Sci. Eng. A 2006, 428, 159-168. [CrossRef]

29. Yu, H.; Sun, Y.; Hu, L.; Wan, Z.; Zhou, H. The effect of Ti addition on microstructure evolution of AZ61 Mg alloy during mechanical milling. J. Alloys Compd. 2017, 704, 537-544. [CrossRef]

30. Lei, R.S.; Wang, M.P.; Li, Z.; Wei, H.G.; Yang, W.C.; Jia, Y.L.; Gong, S. Structure evolution and solid solubility extension of copper-niobium powders during mechanical alloying. Mater. Sci. Eng. A 2011, 528, 4475-4481. [CrossRef]

31. Yu, H.; Sun, Y.; Hu, L.; Zhou, H.; Wan, Z. Microstructural evolution of AZ61-10 at.\%Ti composite powders during mechanical milling. Mater. Des. 2016, 104, 265-275. [CrossRef]

32. Liang, G.; Schulz, R. Synthesis of Mg-Ti alloy by mechanical alloying. J. Mater. Sci. 2003, 38, 1179-1184. [CrossRef]

33. Cao, N.Q.; Narita, K.; Kobayashi, E.; Sato, T. Evolution of the microstructure and mechanical properties of Mg-matrix in situ composites during spark plasma sintering. Powder Metall. 2016, 59, 302-307. [CrossRef]

34. Lee, T.J.; Kim, W.J. Microstructure and tensile properties of magnesium nanocomposites fabricated using magnesium chips and carbon black. J. Magnes. Alloys 2020, 8, 860-872. [CrossRef]

35. Aydin, F.; Sun, Y.; Ahlatci, H.; Turen, Y. Investigation of Microstructure, Mechanical and Wear Behaviour of $\mathrm{B}_{4} \mathrm{C}$ Particulate Reinforced Magnesium Matrix Composites by Powder Metallurgy. Trans. Indian Inst. Met. 2018, 71, 873-882. [CrossRef]

36. Bidulská, J.; KvaCKaj, T.; Pokorny, I.; Bidulsky, R.; Grande, M.A. Identification of the critical pore sizes in sintered and ECAPed aluminium 6xxx alloy. Arch. Metall. Mater. 2013, 58, 371-375. [CrossRef]

37. Bidulská, J.; KvaCKaj, T.; Bidulsky, R.; Grande, M.A. The Porosity Evaluation during ECAP in Aluminium PM Alloy. Acta Phys. Pol. A 2012, 122, 553-556. [CrossRef]

38. Yu, H.; Yu, S.; Wan, Z.; Zhou, H.; Hu, L. Nanocrystalline Ti/AZ61 magnesium matrix composite: Evolution of microstructure and mechanical property during annealing treatment. J. Alloys Compd. 2018, 741, 231-239. [CrossRef]

39. Razavi-Tousi, S.S.; Yazdani-Rad, R.; Manafi, S.A. Effect of volume fraction and particle size of alumina reinforcement on compaction and densification behavior of $\mathrm{Al}-\mathrm{Al}_{2} \mathrm{O}_{3}$ nanocomposites. Mater. Sci. Eng. A 2011, 528, 1105-1110. [CrossRef]

40. Rao, B.S.; Agarwal, A.; Lahiri, D. Carbon Nanotubes: Reinforced Metal Matrix Composites; CRC Press: Boca Raton, FL, USA, 2010; pp. 181-199.

41. Rashad, M.; Pan, F.; Tang, A.; Asif, M.; Hussain, S.; Gou, J.; Mao, J. Improved strength and ductility of magnesium with addition of aluminum and graphene nanoplatelets (Al + GNPs) using semi powder metallurgy method. J. Ind. Eng. Chem. 2015, 23, 243-250. [CrossRef]

42. Yuan, Q.H.; Qiu, Z.Q.; Zhou, G.H.; Zeng, X.S.; Luo, L.; Rao, X.X.; Ding, Y.; Liu, Y. Interfacial design and strengthening mechanisms of AZ91 alloy reinforced with in-situ reduced graphene oxide. Mater. Charact. 2018, 138, 215-228. [CrossRef]

43. Bidulsk, R.; Bidulská, J.; Gobber, F.S.; Kvakaj, T.; Manfredi, D. Case Study of the Tensile Fracture Investigation of Additive Manufactured Austenitic Stainless Steels Treated at Cryogenic Conditions. Materials 2020, 13, 3328. [CrossRef] [PubMed]

44. Murphy, T.F.; Schade, C.T.; Horvay, K.M. Metallographic characterization of porous low-alloy steel samples manufactured using both press-and-sinter and additive manufacturing techniques. Int. J. Powder Metall. 2019, 55, 37-47.

45. Goh, C.S.; Wei, J.; Lee, L.C.; Gupta, M. Properties and deformation behaviour of $\mathrm{Mg}-\mathrm{Y}_{2} \mathrm{O}_{3}$ nanocomposites. Acta Mater. 2007, 55, 5115-5121. [CrossRef]

46. Han, G.; Wang, Z.; Ke, L.; Li, S.; Xian, D.; Du, W. Synthesis of CNT-reinforced AZ31 magnesium alloy composites with uniformly distributed CNTs. Mater. Sci. Eng. A 2015, 628, 350-357. [CrossRef] 